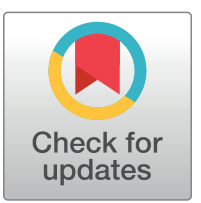

\section{G openaccess}

Citation: Ahn SS, Lee B, Kim D, Jung SM, Lee SW, Park M-C, et al. (2019) Evaluation of macrophage activation syndrome in hospitalised patients with Kikuchi-Fujimoto disease based on the 2016 EULAR/ACR/PRINTO classification criteria. PLoS ONE 14(7): e0219970. https://doi. org/10.1371/journal.pone.0219970

Editor: Mahmoud Abu-Shakra, Soroka University Medical Center, ISRAEL

Received: February 13, 2019

Accepted: July 6, 2019

Published: July 18, 2019

Copyright: ( 2019 Ahn et al. This is an open access article distributed under the terms of the Creative Commons Attribution License, which permits unrestricted use, distribution, and reproduction in any medium, provided the original author and source are credited.

Data Availability Statement: All relevant data are within the manuscript and its Supporting Information files.

Funding: This research was supported by a grant of the Korean Health Technology R\&D Project through the Korean Health Industry Development Institute (KHIDI) funded by the Ministry of Health \& Welfare, Republic of Korea (Grant number: HI18C0919).

RESEARCH ARTICLE

\title{
Evaluation of macrophage activation syndrome in hospitalised patients with Kikuchi-Fujimoto disease based on the 2016 EULAR/ACR/PRINTO classification criteria
}

\section{Sung Soo Ahn ${ }^{1}$, Byeori Lee ${ }^{2}$, Dam Kim ${ }^{1}$, Seung Min Jung ${ }^{1}$, Sang-Won Lee ${ }^{1}$, Min- Chan Park ${ }^{1}$, Yong-Beom Park ${ }^{1}$, Yong Gil Hwang ${ }^{3}$, Jason Jungsik Song ${ }^{1,4 *}$}

1 Division of Rheumatology, Department of Internal Medicine, Yonsei University College of Medicine, Seoul, South Korea, 2 Department of Internal Medicine, Albert Einstein Medical Center Philadelphia, Philadelphia, Pennsylvania, United States of America, 3 Department of Medicine, Division of Rheumatology and Clinical Immunology, University of Pittsburgh, Pittsburgh, Pennsylvania, United States of America, 4 Institute for Immunology and Immunological Diseases, Yonsei University College of Medicine, Seoul, South Korea

* jsksong@yuhs.ac

\section{Abstract}

\section{Background}

To evaluate the impact of macrophage activation syndrome (MAS) on clinical features in patients with Kikuchi-Fujimoto disease (KFD) and to compare the features of MAS in KFD with those of adult-onset Still's disease (AOSD) and systemic lupus erythematosus (SLE).

\section{Methods}

The medical records of febrile patients hospitalised with KFD between November 2005 and April 2017 were reviewed. Patients fulfilling the 2016 classification criteria for MAS were classified as having MAS. Clinical and laboratory features of patients with KFD with and without MAS were evaluated. Poor hospitalisation outcomes were defined as intensive care unit admission or in-hospital mortality. The treatment outcomes of MAS in KFD, AOSD, and SLE were also compared.

\section{Results}

Among 78 patients hospitalised with KFD, 24 (30.8\%) patients had MAS during admission. Patients with KFD and MAS more frequently required glucocorticoid treatment $(66.7 \%$ vs $40.7 \%, p=0.036$ ) and had longer hospital stays than patients with KFD without MAS (12.5 vs 8.5 days, $p<0.001)$. In addition, patients with MAS had worse hospitalisation outcomes than patients without MAS $(29.2 \%$ vs. $0.0 \%, p<0.001)$. Among patients with MAS in KFD, AOSD, and SLE, the number of patients requiring glucocorticoid treatment after 3 months was significantly lower among patients with MAS and KFD (KFD 33.3\%, AOSD 88.9\%, SLE $100 \%, p<0.001)$. 
Competing interests: The authors have declared that no competing interests exist.

\section{Conclusions}

The presence of MAS in KFD was associated with adverse clinical outcomes including higher steroid usage and worse hospitalisation outcomes. However, compared to those with AOSD and SLE, patients with MAS and KFD were less likely to require long-term glucocorticoid treatment.

\section{Introduction}

Kikuchi-Fujimoto disease (KFD), also known as histiocytic necrotising lymphadenitis, is a rare idiopathic inflammatory disease first described in 1972 by Kikuchi and Fujimoto et al $[1,2]$. KFD mainly affects adults younger than 40 years of age and is predominant among Asian populations [3]. The aetiology of KFD is still unknown although various inciting agents, including the Epstein-Barr virus (EBV), human herpesvirus types 6, 7, and 8, herpes simplex virus, and $\mathrm{HIV}$, have been suggested as possible causative agents $[1,2,4]$. KFD typically presents as persistent cervical lymphadenopathy with or without fever [5]. Some patients manifest non-specific systemic symptoms including night sweats, weight loss, nausea, vomiting, hepatosplenomegaly, and headache $[6,7]$. The clinical characteristics of KFD can resemble those of malignant lymphoma, metastatic carcinoma, infectious lymphadenitis, systemic autoimmune diseases, and Mycobacterium tuberculosis infections [8-10]. The overall prognosis of KFD is favourable with a benign, self-limiting course. Although there is no specific treatment for KFD, supportive management with analgesics and antipyretics is usually adequate, leading to spontaneous resolution in several months [6].

In KFD cases with severe clinical presentations, few case reports described co-existence of hemophagocytic lymphohistiocytosis (HLH) [11-18]. HLH is a syndrome of excessive proinflammatory cytokine production due to uncontrolled expansion of T lymphocytes and macrophages, which is characterised by hemophagocytosis, intractable fever, hepatosplenomegaly, cytopenia, hypertriglyceridemia, and hypofibrinogenemia [19, 20]. Although primary HLH is associated with genetic defects in the perforin-mediated cytolytic pathway, macrophage activation syndrome (MAS) is considered to be a secondary form of HLH associated with malignancy, infection, and autoimmune diseases [21]. Because viral infections such as EBV are known to cause HLH by triggering uncontrolled lymphoproliferation [22], there is a concern that KFD can be associated with MAS. While MAS is a potentially life-threatening condition that requires early detection, MAS-specific diagnostic criteria have not yet been fully established. Recently, new classification criteria for MAS were developed by a collaboration of international study groups and were validated in patients with systemic juvenile idiopathic arthritis (sJIA) with excellent specificity [23, 24]. We previously demonstrated that these criteria were also useful for the identification of patients with MAS in adult-onset Still's disease (AOSD) and systemic lupus erythematosus (SLE) to predict poor hospitalisation outcomes [25, 26].

Although MAS may follow a severe and fatal course, the incidence and clinical characteristics of MAS-complicated KFD are still not well understood. In our study, we aimed to evaluate the impact of MAS on the clinical features of KFD and to compare the clinical and laboratory features of patients with MAS complicating KFD, AOSD, and SLE.

\section{Material and methods}

\section{Patient selection and study design}

We retrospectively reviewed the clinical and laboratory data of patients with a diagnosis of KFD between November 2005 and April 2017 in two tertiary hospitals in the Yonsei University 
Health System located in Shinchon and Gangnam district of Seoul, Korea. The inclusion criteria were as follows: (i) patients who were admitted with fever; (ii) patients with diagnosis of KFD that was confirmed pathologically; (iii) patients with ferritin level assessment; (iv) patients without concurrent autoimmune disease/infection. Finally, 78 patients were included in this study. The flowchart for patient selection is shown in S1 Fig. The clinical and laboratory data of patients with MAS in AOSD and SLE according to the 2016 classification criteria were obtained using a pre-existing dataset used in a previous study $[25,26]$, and all data were fully anonymized for analysis. This study was conducted in accordance with the Declaration of Helsinki and was approved by the Institutional Review Board of Severance Hospital (IRB approval number 4-2018-0624). The requirement to obtain informed consent was waived because of the retrospective nature of the study.

\section{Definition of patients with MAS according to the 2016 classification criteria}

According to the 2016 EULAR/ACR/PRINTO classification criteria for MAS [23, 24], we classified patients as having MAS when they presented with fever, a ferritin level of $\geq 684 \mathrm{ng} / \mathrm{mL}$, and fulfilled more than 2 of the following 4 criteria: platelet count $\leq 181,000 / \mathrm{mL}$, aspartate aminotransferase (AST) level $>48$ units $/ \mathrm{L}$, triglyceride level $>156 \mathrm{mg} / \mathrm{dL}$, and fibrinogen level $\leq 360 \mathrm{mg} / \mathrm{dL}$. In addition, patients with MAS were divided into two groups: patients having MAS on admission and those who developed MAS after admission.

\section{Collection of clinical and laboratory variables}

The clinical data collected included age, sex, length of hospital stay, in-hospital mortality, intensive care unit admission, and treatment. Poor hospitalisation outcomes were defined as intensive care unit admission or in-hospital mortality. The clinical manifestations of KFD included the presence of hepatomegaly, splenomegaly, skin rash, and joint pain. Baseline laboratory variables included white blood cells, neutrophils, lymphocyte and platelet counts, erythrocyte sedimentation rate, and levels of haemoglobin, C-reactive protein (CRP), creatinine, AST, alanine aminotransferase (ALT), albumin, ferritin, lactate dehydrogenase (LDH), fibrinogen, and triglycerides. As fibrinogen and triglyceride levels were not measured regularly, the levels obtained within 3 days of the date of laboratory data selection were included in the analysis.

\section{Calculation of the hemophagocytic syndrome score (HScore) and patients fulfilling the HLH-2004 criteria}

The HScore was developed to evaluate individual risk for the presence of hemophagocytic syndrome [27] and is also useful to identify the risk of having reactive hemophagocytic syndrome in patients with rheumatic diseases [28]. The HScore and the probability of having hemophagocytic syndrome were calculated using an online calculator (saintantoine.aphp.fr/score). Furthermore, the proportion of patients fulfilling the HLH-2004 criteria was estimated as previously described [29].

\section{Statistical analysis}

Continuous variables were presented as medians with interquartile ranges (IQR), and categori$\mathrm{cal}$ variables were presented as frequencies and percentages. Continuous variables were compared using the Kruskal-Wallis test or Mann-Whitney U test, and categorical variables were compared using the chi-square or Fisher's exact test, as appropriate. Kaplan-Meier analysis 
Table 1. Clinical characteristics of patients with KFD with and without MAS.

\begin{tabular}{|c|c|c|c|}
\hline & Without MAS $(n=54)$ & With MAS $(n=24)$ & p-value \\
\hline \multicolumn{4}{|l|}{ Demographic data } \\
\hline Age, years & $26.0(21.0-35.0)$ & $40.0(32.5-55.0)$ & $<0.001$ \\
\hline Female sex & $37(68.5)$ & $15(62.5)$ & 0.605 \\
\hline \multicolumn{4}{|l|}{ Clinical manifestations } \\
\hline Hepatomegaly & $6(11.1)$ & $0(0.0)$ & 0.169 \\
\hline Splenomegaly & $12(22.2)$ & $7(29.2)$ & 0.512 \\
\hline Skin rash & $8(14.9)$ & $7(29.2)$ & 0.140 \\
\hline Joint pain & $1(1.9)$ & $3(12.5)$ & 0.084 \\
\hline \multicolumn{4}{|l|}{ Treatment } \\
\hline Glucocorticoid treatment & $22(40.7)$ & $16(66.7)$ & 0.036 \\
\hline Immunosuppressive treatment & $1(1.9)$ & $3(12.5)$ & 0.084 \\
\hline Hydroxychloroquine & $1(1.9)$ & $2(8.3)$ & \\
\hline Cyclosporine & $0(0.0)$ & $1(4.2)$ & \\
\hline \multicolumn{4}{|l|}{ Clinical course } \\
\hline Length of stay in hospital (days) & $8.5(6.0-11.0)$ & $12.5(10.5-32.0)$ & $<0.001$ \\
\hline In-hospital mortality & $0(0.0)$ & $5(20.8)$ & 0.002 \\
\hline Intensive unit care & $0(0.0)$ & $7(29.2)$ & $<0.001$ \\
\hline
\end{tabular}

Data expressed as median (interquartile range) or n (\%). KFD, Kikuchi-Fujimoto disease; MAS, macrophage activation syndrome.

and the log-rank test were used to compare the survival probability among the groups. All statistical analyses were performed using MedCalc statistical software version 18.6 (MedCalc Software, Ostend, Belgium) or GraphPad Prism software version 5.0 (GraphPad Software, San Diego, California, USA). In all statistical analyses, a two-tailed $\mathrm{p}<0.05$ was considered statistically significant.

\section{Results}

\section{Baseline characteristics of patients with and without MAS}

Of the 78 patients included in the study, 24 (30.8\%) were classified as having MAS during admission (Table 1). Among the 24 patients, 20 (83.3\%) had MAS on admission, and 4 (16.7\%) developed MAS after admission. Although the clinical manifestations were not different between patients with and without MAS, patients with MAS were older and had a longer hospital stays, and the proportion of patients with poor hospitalisation outcomes was significantly higher in patients with MAS $(29.2 \%$ vs. $0.0 \%, \mathrm{p}<0.001)$. In addition, the median HScore (97.0 [IQR 68.0-128.5] vs 49.0 [IQR 33.0-72.0]) and the probability of having hemophagocytic syndrome were higher in patients with MAS than in patients without MAS (all $\mathrm{p}<0.001$ ) (Fig $1 \mathrm{~A}$ and $1 \mathrm{~B}$ ). Furthermore, the proportion of patients requiring glucocorticoid treatment was significantly higher in patients with MAS (66.7\% vs $40.7 \%, \mathrm{p}=0.036$ ). Regarding laboratory findings, patients with MAS had higher CRP, ALT, and LDH levels and a lower lymphocyte count and albumin levels than those without MAS. Among the laboratory variables selected for MAS classification, higher AST and ferritin levels and lower platelet counts were observed in patients with MAS; however, the differences between triglyceride and fibrinogen levels were not significant (Table 2). Of the 19/78 (24.4\%) patients who had undergone a bone marrow study, only 2 patients in the MAS group were found to have hemophagocytosis. 
A

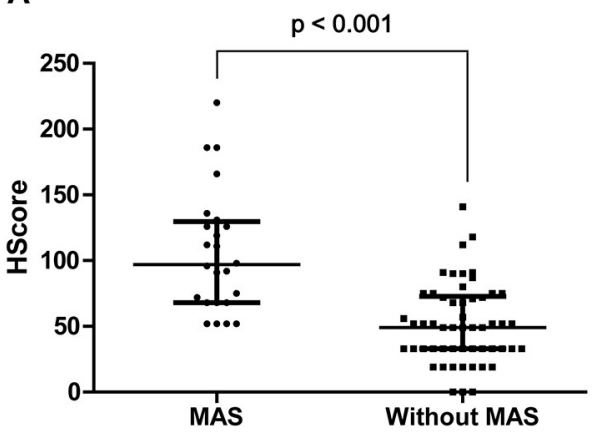

B

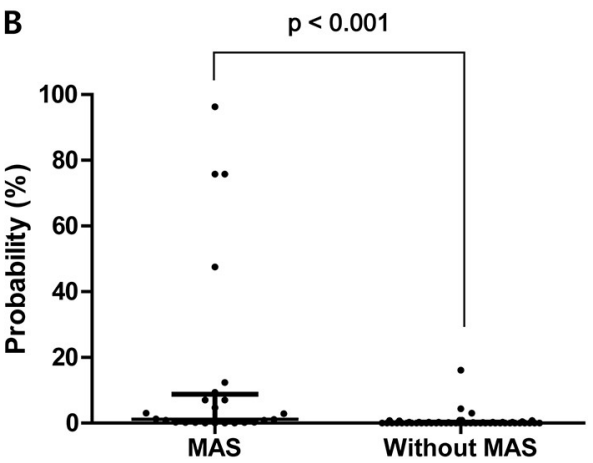

Fig 1. HScore and the probability of having hemophagocytic syndrome in patients with KFD with and without MAS. Comparison of HScore (A) and the probability of having hemophagocytic syndrome (B) in patients with KFD with and without MAS. HScore, hemophagocytic syndrome score; KFD, Kikuchi-Fujimoto disease; MAS, macrophage activation syndrome.

https://doi.org/10.1371/journal.pone.0219970.g001

\section{Clinical and laboratory findings of patients with KFD and in-hospital mortality}

As MAS in KFD is not a well-described complication, we further analysed the clinical and laboratory features of patients with KFD and in-hospital mortality (Table 3). All patients in our study who died in the hospital had MAS, were older than 50 years of age and did not have any

Table 2. Comparison of baseline laboratory findings of patients with and without MAS.

\begin{tabular}{|c|c|c|c|}
\hline Variable & Without MAS $(n=54)$ & With MAS $(n=24)$ & p-value \\
\hline \multicolumn{4}{|l|}{ General laboratory variables } \\
\hline WBC count $(/ \mu \mathrm{L})$ & $3475.0(2350.0-5000.0)$ & $3285.0(2335.0-5905.0)$ & 0.996 \\
\hline Hemoglobin (g/dL) & $12.5(11.7-13.4)$ & $11.7(10.3-13.2)$ & 0.102 \\
\hline Neutrophil count $(/ \mu \mathrm{L})$ & $1925.0(1310.0-3050.0)$ & $2206.5(1375.0-4833.5)$ & 0.378 \\
\hline Lymphocyte count $(/ \mu \mathrm{L})$ & $1045.0(860.0-1370.0)$ & $600.0(490.0-940.0)$ & $<0.001$ \\
\hline $\operatorname{ESR}(\mathrm{mm} / \mathrm{h})$ & $48.5(27.0-64.0)$ & $52.5(39.5-72.5)$ & 0.242 \\
\hline $\mathrm{CRP}(\mathrm{mg} / \mathrm{L})$ & $15.0(7.5-37.1)$ & $52.6(27.7-97.1)$ & $<0.001$ \\
\hline Creatinine (mg/dL) & $0.7(0.6-0.8)$ & $0.7(0.5-1.1)$ & 0.349 \\
\hline ALT (IU/L) & $21.5(14.0-38.0)$ & $44.5(23.0-153.0)$ & 0.003 \\
\hline $\operatorname{Albumin}(\mathrm{g} / \mathrm{dL})$ & $4.0(3.7-4.3)$ & $3.4(3.1-3.7)$ & $<0.001$ \\
\hline $\mathrm{LDH}(\mathrm{IU} / \mathrm{L})$ & $439.5(291.0-611.0)$ & $771.5(460.0-1213.5)$ & 0.003 \\
\hline \multicolumn{4}{|c|}{ Laboratory variables selected for MAS classification } \\
\hline Platelet count $(\times 1000 / \mu \mathrm{L})$ & $195.5(155.0-260.0)$ & $139.0(94.5-184.0)$ & $<0.001$ \\
\hline AST (IU/L) & $29.0(22.0-39.0)$ & $93.5(62.5-191.0)$ & $<0.001$ \\
\hline Ferritin $(\mathrm{ng} / \mathrm{mL})$ & $242.8(112.0-405.2)$ & $1449.7(812.9-4463.1)$ & $<0.001$ \\
\hline Triglyceride $(\mathrm{mg} / \mathrm{dL})^{9}$ & $89.0(60.0-106.5)$ & $133.0(90.3-161.3)$ & 0.076 \\
\hline Fibrinogen $(\mathrm{mg} / \mathrm{dL})^{\S}$ & $342.0(338.0-346.0)$ & $317.5(227.5-401.0)$ & 0.695 \\
\hline \multicolumn{4}{|l|}{ Bone marrow biopsy findings* } \\
\hline Presence of hemophagocytosis & $0 / 7(0.0)$ & $2 / 12(16.7)$ & 0.509 \\
\hline
\end{tabular}

Data are expressed as median (interquartile range) or n (\%). MAS, macrophage activation syndrome; WBC, white blood cell; ESR, erythrocyte sedimentation rate; CRP, C-reactive protein; ALT, alanine aminotransferase; LDH, lactate dehydrogenase; AST, aspartate aminotransferase.

${ }^{9}$ Number confined to patients who underwent each test $(\mathrm{n}=23)$.

${ }^{5}$ Number confined to patients who underwent each test $(\mathrm{n}=10)$.

*Number confined to patients who underwent each test $(n=19)$.

https://doi.org/10.1371/journal.pone.0219970.t002 
Table 3. The clinical and laboratory features of patients with KFD and in-hospital mortality.

\begin{tabular}{|c|c|c|c|c|c|c|c|}
\hline $\begin{array}{c}\text { Case } \\
\text { number }\end{array}$ & Age/Sex & Main symptom & $\begin{array}{l}\text { Initial/highest ferritin level } \\
\qquad(\mathrm{ng} / \mathrm{mL})\end{array}$ & $\begin{array}{c}\text { Initial/lowest platelet } \\
\text { count }(/ \mu \mathrm{L})\end{array}$ & $\begin{array}{c}\text { Initial/highest AST } \\
\text { level (IU/L) }\end{array}$ & $\begin{array}{l}\text { Time to death } \\
\text { (days) }\end{array}$ & Cause of death \\
\hline 1 & 68/Male & Fever & $13308.3 / 15000.0$ & $133000 / 27000$ & $178 / 24650$ & Death in day 8 & $\begin{array}{l}\text { Multi-organ } \\
\text { failure }\end{array}$ \\
\hline 2 & $\begin{array}{c}52 / \\
\text { Female }\end{array}$ & $\begin{array}{l}\text { Fever, skin rash, } \\
\text { joint pain }\end{array}$ & $14399.9 / 14399.9$ & $69000 / 20000$ & $132 / 134$ & Death in day 11 & $\begin{array}{l}\text { Multi-organ } \\
\text { failure }\end{array}$ \\
\hline 3 & 56/Male & Fever, myalgia & $441.8 / 1896.6$ & $346000 / 7000$ & $204 / 8320$ & Death in day 24 & Sepsis \\
\hline 4 & $\begin{array}{c}61 / \\
\text { Female }\end{array}$ & $\begin{array}{l}\text { Fever, headache, } \\
\text { nausea }\end{array}$ & $15363.6 / 15363.6$ & $92000 / 16000$ & $96 / 394$ & Death in day 32 & $\begin{array}{l}\text { Multi-organ } \\
\text { failure }\end{array}$ \\
\hline 5 & $\begin{array}{c}57 / \\
\text { Female }\end{array}$ & Sore throat, fever & $528.9 / 38765.3$ & $97000 / 21000$ & $22 / 483$ & $\begin{array}{l}\text { Death in day } \\
281\end{array}$ & $\begin{array}{l}\text { Multi-organ } \\
\text { failure }\end{array}$ \\
\hline
\end{tabular}

KFD, Kikuchi-Fujimoto disease.

specific clinical manifestations. Among MAS patients with KFD $(n=24)$, patients aged $\geq 50$ years had a higher mortality rate than those aged $<50$ years $(\mathrm{p}=0.003)$ (Fig 2$)$. During the disease course, patients with MAS had increasing ferritin and AST levels, while platelet counts decreased. Most deaths occurred within 90 days, and among the five patients who died, the cause of death was multi-organ failure in 4 patients and sepsis in 1 patient (Table 3). Hepatosplenomegaly was only observed in one patient, and no patients had co-existing comorbidities with the exception of gout in one patient.

\section{Clinical and laboratory features among patients with MAS in KFD, AOSD, and SLE}

Next, we compared the clinical and laboratory features among patients with MAS in KFD, AOSD and SLE. Clinical and laboratory data of patients with AOSD or SLE and MAS used for comparison were obtained from the dataset of previous studies [25, 26]. Patients with AOSD were older than those with SLE, and the proportion of female patients was the lowest in patients with KFD. The presence of lymphadenopathy was significantly higher in patients with KFD than in those with AOSD or SLE (Table 4). There were no differences in the median HScore (KFD 97.0 [IQR 68.0-128.5] vs AOSD 108.5 [IQR 102.0-150.0] vs SLE 111.0 [IQR 76.0-137.0], $\mathrm{p}=0.296$ ) or the probability of having hemophagocytic syndrome among patients with MAS in KFD, AOSD, and SLE (S2A and S2B Fig, p = 0.296). In addition, the number of patients fulfilling the HLH-2004 criteria was 2/24 (8.3\%), 6/36 (16.7\%), and 3/54 (5.6\%) in $\mathrm{KFD}$, AOSD, and SLE, respectively, without a statistical difference $(\mathrm{p}=0.210)$. Comparison of laboratory variables between the groups showed that elevated white blood cells, neutrophils, lymphocyte count, and CRP levels were prominent in patients with AOSD, while decreased haemoglobin and albumin levels were characteristic in patients with SLE. Regarding laboratory variables selected for MAS classification, platelet count and ferritin levels were the highest in patients with AOSD, while triglyceride levels were the lowest in patients with KFD (Table 4).

\section{Comparison of 90-day mortality and treatment among patients with MAS in KFD, AOSD, and SLE}

To evaluate the prognosis of patients with MAS in different diseases, we compared the 90-day mortality among patients with MAS in KFD, AOSD, and SLE by using Kaplan-Meier analysis with the log-rank test. The number of patients with 90-day mortality in KFD, AOSD, and SLE was 4 (16.7\%), 12 (33.3\%), and 15 (27.8\%) patients, respectively. Kaplan-Meier survival analysis showed that the survival probability among patients with MAS in KFD, AOSD, and SLE 


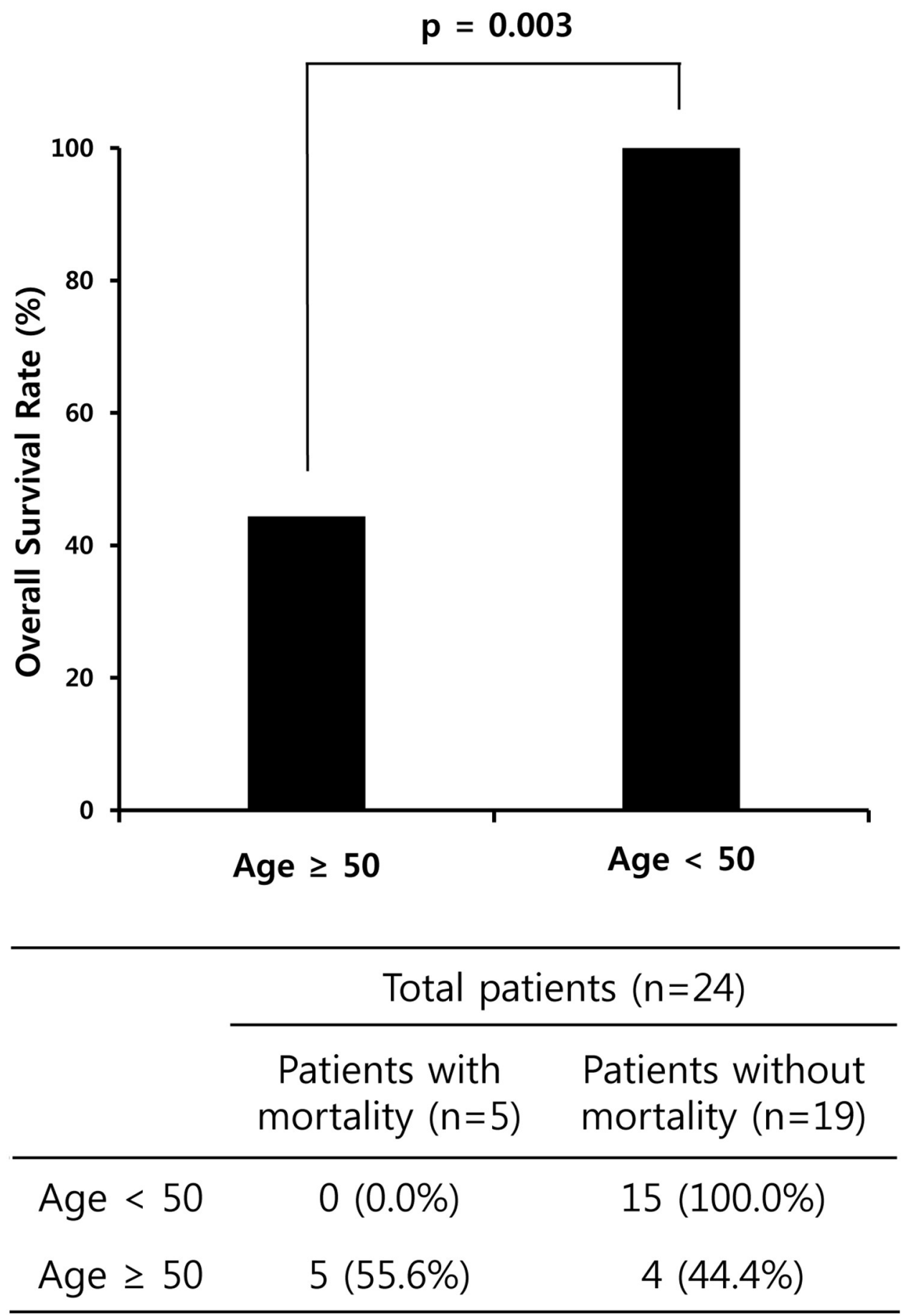

Fig 2. Comparison of the overall survival rate of patients with KFD and MAS according to age. In MAS patients with KFD, patients aged $\geq 50$ years had a higher mortality rate than those aged $<50$ years. KFD, Kikuchi-Fujimoto disease; MAS, macrophage activation syndrome.

https://doi.org/10.1371/journal.pone.0219970.g002

was not statistically significant $(\mathrm{p}=0.427)$ ( $\mathrm{S} 3 \mathrm{Fig}$ ). However, the treatment for patients with $\mathrm{KFD}$, AOSD, and SLE was different according to the underlying disease, and patients with KFD had a higher rate of glucocorticoid cessation after 3 months (KFD 66.7\%, AOSD 11.1\%, SLE $0.0 \%, \mathrm{p}<0.001$ ) and had fewer immunosuppressive agents administered (Table 4). 
Table 4. Clinical and laboratory features in patients with MAS in KFD, AOSD, and SLE.

\begin{tabular}{|c|c|c|c|c|}
\hline Variable & $\operatorname{KFD}(n=24)$ & $\operatorname{AOSD}(n=36)$ & SLE $(n=54)$ & p-value \\
\hline \multicolumn{5}{|l|}{ Demographic data } \\
\hline Age, years & $40.0(32.5-55.0)$ & $47.5(36.0-57.5)^{* *}$ & $37.0(26.0-49.0)$ & 0.010 \\
\hline Female sex & $15(62.5)^{\mathrm{b}}$ & $34(94.4)$ & $46(85.2)^{\S}$ & 0.004 \\
\hline \multicolumn{5}{|l|}{ Clinical manifestations } \\
\hline Hepatomegaly & $0(0.0)$ & $4(11.1)$ & $8(14.8)$ & 0.143 \\
\hline Splenomegaly & $7(29.2)$ & $10(27.8)$ & $16(29.6)$ & 0.982 \\
\hline Lymphadenopathy & $24(100.0)^{c}$ & $16(44.4)$ & $29(53.7)^{\S \S \S}$ & $<0.001$ \\
\hline \multicolumn{5}{|l|}{ General laboratory variables } \\
\hline WBC count $(/ \mu \mathrm{L})$ & $3285.0(2335.0-5905.0)^{\mathrm{c}}$ & $10630.0(6915.0-6130.0)^{* * *}$ & $2830.0(1800.0-6210.0)$ & $<0.001$ \\
\hline Hemoglobin (g/dL) & $11.7(10.3-13.2)$ & $10.9(10.0-11.7)^{* *}$ & $10.1(8.7-11.0)^{\S \S \S}$ & $<0.001$ \\
\hline Neutrophil count $(/ \mu \mathrm{L})$ & $2206.5(1375.0-4833.5)^{c}$ & $8575.0(4780.0-14325.0)^{* * *}$ & $2015.0(1230.0-4320.0)$ & $<0.001$ \\
\hline Lymphocyte count $(/ \mu \mathrm{L})$ & $600.0(490.0-940.0)^{\mathrm{a}}$ & $899.0(655.0-1225.0)^{* * *}$ & $491.4(310.0-790.0)$ & $<0.001$ \\
\hline $\operatorname{ESR}(\mathrm{mm} / \mathrm{h})$ & $52.5(39.5-72.5)$ & $61.0(29.0-83.0)$ & $42.5(29.0-70.0)$ & 0.186 \\
\hline $\mathrm{CRP}(\mathrm{mg} / \mathrm{L})$ & $52.6(27.7-97.1)^{\mathrm{a}}$ & $96.4(50.2-143.8)^{* * *}$ & $13.5(5.5-59.9)^{\S \S}$ & $<0.001$ \\
\hline ALT (IU/L) & $44.5(23.0-153.0)$ & $36.0(23.5-117.5)$ & $38.5(24.0-68.0)$ & 0.729 \\
\hline Albumin (g/dL) & $3.4(3.1-3.7)$ & $3.1(3.0-3.6)^{*}$ & $2.9(2.4-3.3)^{\S \S}$ & 0.011 \\
\hline \multicolumn{5}{|l|}{ Laboratory variables selected for MAS classification } \\
\hline Platelet count $(\times 1000 / \mu \mathrm{L})$ & $139.0(94.5-184.0)^{\mathrm{a}}$ & $203.5(140.0-292.0)^{* * *}$ & $109.5(91.0-155.0)$ & $<0.001$ \\
\hline AST (IU/L) & $93.5(62.5-191.0)$ & $76.5(42.0-207.5)$ & $89.0(50.0-183.0)$ & 0.778 \\
\hline Ferritin $(\mathrm{ng} / \mathrm{mL})$ & $1449.7(812.9-4463.1)^{\mathrm{b}}$ & $6773.4(2567.1-14610.2)^{* * *}$ & $1483.5(754.9-2324.7)$ & $<0.001$ \\
\hline Triglyceride (mg/dL) & $133.0(90.3-161.3)$ & $168.0(126.7-223.5)$ & $173.0(145.5-274.0)^{\S \S}$ & 0.026 \\
\hline Fibrinogen $(\mathrm{mg} / \mathrm{dL})$ & $317.5(227.5-401.0)$ & $302.0(202.5-406.3)$ & $253.0(170.0-329.0)$ & 0.320 \\
\hline \multicolumn{5}{|l|}{ Clinical course and treatment outcome } \\
\hline Length of stay in hospital (days) & $12.5(10.5-32.0)$ & $22.5(13.0-41.5)$ & $19.0(14.0-29.0)$ & 0.257 \\
\hline Glucocorticoid treatment cessation at 3 months ${ }^{\dagger}$ & $16(66.7)^{\mathrm{c}}$ & $4(11.1)^{*}$ & $0(0.0)^{\S \S \S}$ & $<0.001$ \\
\hline Number of Immunosuppressive treatments administered ${ }^{\ddagger}$ & & & & 0.018 \\
\hline $0-1$ & $24(100.0)^{\mathrm{b}}$ & $26(72.2)$ & $45(83.3)^{\S}$ & \\
\hline$\geq 2$ & $0(0.0)$ & $10(27.8)$ & $9(16.7)$ & \\
\hline
\end{tabular}

Data expressed as median (interquartile range) or $\mathrm{n}(\%)$.

${ }^{\dagger}$ Glucocorticoid treatment and the dosage of glucocorticoids in patients with mortality or who were lost to follow-up were counted on the last date of follow-up.

${ }^{\ddagger}$ Includes treatment with disease modifying anti-rheumatic drugs, biologics, cyclosporine, and etoposide/cyclophosphamide.

${ }^{\mathrm{a}}$ Difference between patients with KFD and AOSD. $\mathrm{p}<0.05$;

${ }^{\mathrm{b}}$ Difference between patients with KFD and AOSD, $\mathrm{p}<0.01$;

${ }^{c}$ Difference between patients with KFD and AOSD, $\mathrm{p}<0.001$.

${ }^{\S}$ Difference between patients with KFD and SLE. $\mathrm{p}<0.05$;

${ }^{\$ S}$ Difference between patients with KFD and SLE, $p<0.01$;

${ }^{\$ \$}$ Difference between patients with KFD and SLE, $\mathrm{p}<0.001$

${ }^{*}$ Difference between patients with AOSD and SLE, $\mathrm{p}<0.05$;

${ }^{* *}$ Difference between patients with AOSD and SLE, $\mathrm{p}<0.01$;

*** Difference between patients with AOSD and SLE, $\mathrm{p}<0.001$.

MAS, macrophage activation syndrome; KFD, Kikuchi-Fujimoto disease; AOSD, adult onset Still's disease; SLE, systemic lupus erythematosus; WBC, white blood cell; ESR, erythrocyte sedimentation rate; CRP, C-reactive protein; ALT, alanine aminotransferase; AST, aspartate aminotransferase.

https://doi.org/10.1371/journal.pone.0219970.t004

\section{Discussion}

While KFD is pathologically characterised by a proliferation of activated cytotoxic T lymphocytes and histiocytes with central necrotic areas in lymph nodes, HLH is characterised by hemophagocytosis, engulfing erythrocytes, and leukocytes by histiocyte in the bone marrow or 
liver. Therefore, both KFD and HLH are associated with abnormal histiocyte activation. In addition, inflammatory cytokines such as tumor necrosis factor (TNF)- $\alpha$, interleukin (IL)-1, and IL-6 are also implicated in the pathogenesis of both MAS and severe cases of KFD [30, 31]. Therefore, although it is possible that HLH can be accompanied by KFD, the association between KFD and HLH is not well understood. In this study, by using the 2016 EULAR/ACR/ PRINTO classification criteria, we found the incidence of MAS, a secondary form of HLH, was $30.8 \%$ in our study population of pathologically confirmed KFD. Because we included only febrile hospitalised patients with KFD, our study population might have been skewed towards those having severe laboratory abnormalities in tertiary referral centres; however, the association of MAS in KFD is an interesting finding that requires clinical attention.

KFD patients with MAS experienced longer hospital stays and worse hospitalisation outcomes, including higher rates of intensive care unit stays and in-hospital mortality than in patients without MAS. In addition, the proportion of patients with KFD requiring glucocorticoid treatment was significantly higher in patients with MAS than in patients without MAS. All 5 cases of mortality in our cohort were observed in patients with MAS who were over the age of 50. Compared to patients aged $<50$ years, those aged 50 years and older had significantly higher mortality in KFD with MAS. These findings suggest that older KFD patients with MAS might be especially associated with poor prognosis.

MAS presents as non-remitting fever, generalised lymphadenopathy, hepatosplenomegaly, pancytopenia, high ferritin, and low fibrinogen levels [32]. Since there are no disease-specific clinical manifestations or laboratory abnormalities of MAS, and many of the symptoms resemble those of KFD itself, the clinician's suspicion is critical for the diagnosis. In addition, even though hyperferritinemia is a prerequisite in the 2016 criteria for MAS, alternative diagnoses which can be associated with elevated ferritin levels such as sepsis and catastrophic antiphospholipid syndrome should be excluded [33]. In our study, the difference in clinical manifestations between patients with KFD with and without MAS was not significant. On the other hand, in terms of laboratory findings, patients with KFD and MAS had higher CRP, LDH, ferritin, AST, and ALT levels and lower platelet counts, lymphocyte count, and albumin levels than patients with KFD without MAS. Importantly, in our study, a higher proportion of patients with KFD and MAS were treated with steroids than patients without MAS. Monitoring for MAS in patients with KFD could be clinically important, as patients without MAS could be treated with supportive care, while those with MAS might require steroids or additional second-line treatments such as cyclosporine, anti-cytokine therapy, or chemotherapy [34].

Comparison of clinical and laboratory features between patients with MAS-associated KFD, AOSD, and SLE showed that they had different characteristics. Notably, a higher proportion of patients with KFD were able to stop steroids within 3 months compared to patients with SLE or AOSD. Additionally, fewer immunosuppressive agents were administered to patients with MAS and KFD than to patients with MAS and AOSD or SLE. Hence, the clinical course of MAS-associated KFD is milder than MAS with SLE or AOSD, suggesting that the treatment of MAS should be tailored to the underlying diseases.

In our data, 50\% (12/24) of KFD patients with MAS received bone marrow evaluation and only $16.7 \%(2 / 12)$ patients were found to have hemophagocytosis. Although this is a small number of patients in a retrospective study, the incidence of hemophagocytosis in our KFD patients were lower than other studies with autoimmune diseases. In a recent review paper of MAS with autoimmune diseases, $42 \%-100 \%$ were positive for bone marrow hemophagocytosis in patients with SLE, Kawasaki disease, and sJIA [35]. In our recent MAS study with AOSD patients, 50\% was positive for hemophagocytosis in bone marrow evaluation [26]. It is possible that our KFD patients might have received bone marrow biopsy in the early course which 
often makes the result negative [21]. It is also possible that macrophage activation in lymph nodes might be enough to drive MAS in KFD. Although in the autoimmune area, bone marrow analysis is not always required for diagnosis of MAS, it is of interest to validate our finding in future studies.

The strength of this study is that, to our knowledge, it is the first study to investigate the incidence and clinical outcomes of MAS in patients with KFD. We only included patients whose diagnoses were confirmed pathologically, further validating our results. Since KFD is prevalent in young Asian women, we have a large population of patients with KFD at our institution, enabling recruitment of a statistically significant number of patients for this study. However, our study also has several limitations. First, it is a retrospective study, and the data were collected by reviewing the hospital's medical records. Second, there were patients who did not have ferritin, fibrinogen, and triglyceride level results; this might have influenced patient selection and classification resulting in selection bias because clinically severe patients may undergo more blood tests. Therefore, the incidence of MAS in our study might be relevant in patients with KFD and severe clinical or laboratory features. Third, data regarding proinflammatory cytokines (TNF- $\alpha$, interferon- $\gamma$, IL-1, IL-6, and soluble CD163) associated with MAS were not obtainable because the following tests were not available in our hospitals [36, 37]. Because these cytokines are known to play an important role in the pathogenesis of MAS $[30,31]$, assessment of such tests in future studies would provide additional significance. Fourth, because the 2016 classification criteria for MAS have only been validated in patients with sJIA, caution should be made when applying the criteria to non-sJIA diseases. HLH-2004 criteria may be more suitable for non-sJIA diseases. Because a majority of patients had not undergone tests of bone marrow study, natural killer cell activity, and soluble CD25, we could not validate our finding using HLH-2004 criteria.

In conclusion, our findings suggest that the application of the 2016 EULAR/ACR/PRINTO criteria for MAS in hospitalised patients with KFD can be useful in detecting MAS. In addition, although the clinical and laboratory findings were different based on the underlying autoimmune disease, the presence of MAS based on the 2016 EULAR/ACR/PRINTO criteria was associated with adverse patient prognosis. Especially older patients with KFD who presents with features of MAS may be associated with a high mortality rate and may need special attention. Therefore, monitoring patients with KFD according to the 2016 criteria for MAS might aid in predicting patient prognosis and the stratification of high-risk patients.

\section{Supporting information}

S1 Fig. Flowchart for patient selection. The flowchart for patient inclusion. (TIF)

S2 Fig. HScore and the probability of having hemophagocytic syndrome among patients with MAS in KFD, AOSD, and SLE. Comparison of HScore (A) and the probability of having hemophagocytic syndrome (B) in patients with MAS and KFD, AOSD, or SLE. HScore; hemophagocytic syndrome score; MAS, macrophage activation syndrome; KFD, Kikuchi-Fujimoto disease; AOSD, adult onset Still's disease; SLE, systemic lupus erythematosus. (TIF)

S3 Fig. Kaplan-Meier survival curve of 90-day mortality among patients with MAS in KFD, AOSD, and SLE. Comparison of survival probability among patients with MAS in KFD, AOSD, and SLE. MAS, macrophage activation syndrome; KFD, Kikuchi-Fujimoto disease; AOSD, adult onset Still's disease; SLE, systemic lupus erythematosus.

(TIF) 
S1 File. The clinical data of study patients. The raw data of this study are shown in the excel file.

(XLSX)

\section{Author Contributions}

Conceptualization: Jason Jungsik Song.

Data curation: Sung Soo Ahn, Sang-Won Lee.

Formal analysis: Sung Soo Ahn.

Funding acquisition: Jason Jungsik Song.

Methodology: Byeori Lee.

Project administration: Byeori Lee, Dam Kim, Sang-Won Lee, Yong-Beom Park, Jason Jungsik Song.

Resources: Yong-Beom Park.

Supervision: Min-Chan Park, Jason Jungsik Song.

Validation: Byeori Lee, Dam Kim, Seung Min Jung, Jason Jungsik Song.

Visualization: Sung Soo Ahn.

Writing - original draft: Sung Soo Ahn.

Writing - review \& editing: Seung Min Jung, Sang-Won Lee, Min-Chan Park, Yong Gil Hwang, Jason Jungsik Song.

\section{References}

1. Fujimoto Y. Cervical subacute necrotizing lymphadenitis. A new clinicopathological entity. Intern Med. 1972; 20:920-7.

2. Kikuchi M. Lymphadenitis showing focal reticulum cell hyperplasia with nuclear debris and phagocytes: a clinicopathological study. Acta Haematol Jpn. 1972; 35:379-80.

3. Fiorella ML, Gelardi M, Marzullo A, Sabattini E, Fiorella R. Kikuchi-Fujimoto disease: an uncommon cause of neck swelling. European archives of oto-rhino-laryngology: official journal of the European Federation of Oto-Rhino-Laryngological Societies (EUFOS): affiliated with the German Society for OtoRhino-Laryngology—Head and Neck Surgery. 2017; 274(3):1761-4. Epub 2016/06/19. https://doi.org/ 10.1007/s00405-016-4147-6 PMID: 27317565.

4. Hall LD, Eminger LA, Hesterman KS, Heymann WR. Epstein-Barr virus: dermatologic associations and implications: part I. Mucocutaneous manifestations of Epstein-Barr virus and nonmalignant disorders. J Am Acad Dermatol. 2015; 72(1):1-19; quiz -20. Epub 2014/12/17. https://doi.org/10.1016/.jjaad.2014. 07.034 PMID: 25497917.

5. Mathew LM, Kapila R, Schwartz RA. Kikuchi-Fujimoto disease: a diagnostic dilemma. International journal of dermatology. 2016; 55(10):1069-75. Epub 2016/05/22. https://doi.org/10.1111/ijd.13314 PMID 27207311.

6. Deaver D, Horna P, Cualing H, Sokol L. Pathogenesis, diagnosis, and management of Kikuchi-Fujimoto disease. Cancer Control. 2014; 21(4):313-21. Epub 2014/10/14. https://doi.org/10.1177/ 107327481402100407 PMID: 25310212.

7. Hutchinson CB, Wang E. Kikuchi-Fujimoto disease. Arch Pathol Lab Med. 2010; 134(2):289-93. Epub 2010/02/04. PMID: 20121621.

8. Bosch X, Guilabert A. Kikuchi-Fujimoto disease. Orphanet journal of rare diseases. 2006; 1:18. Epub 2006/05/26. https://doi.org/10.1186/1750-1172-1-18 PMID: 16722618.

9. Ramirez AL, Johnson J, Murr AH. Kikuchi-Fujimoto's disease: an easily misdiagnosed clinical entity. Otolaryngology —head and neck surgery: official journal of American Academy of Otolaryngology-Head and Neck Surgery. 2001; 125(6):651-3. Epub 2001/12/18. https://doi.org/10.1067/mhn.2001.120431 PMID: 11743471. 
10. Nayak HK, Mohanty PK, Mallick S, Bagchi A. Diagnostic dilemma: Kikuchi's disease or tuberculosis? BMJ case reports. 2013; 2013. Epub 2013/02/01. https://doi.org/10.1136/bcr-2012-008026 PMID: 23365168.

11. Chmait RH, Meimin DL, Koo CH, Huffaker J. Hemophagocytic syndrome in pregnancy. Obstet Gynecol. 2000; 95(6 Pt 2):1022-4. Epub 2000/05/16. PMID: 10808012.

12. Kucukardali Y, Solmazgul E, Kunter E, Oncul O, Yildirim S, Kaplan M. Kikuchi-Fujimoto Disease: analysis of 244 cases. Clin Rheumatol. 2007; 26(1):50-4. Epub 2006/03/16. https://doi.org/10.1007/s10067006-0230-5 PMID: 16538388.

13. Lee HY, Huang YC, Lin TY, Huang JL, Yang CP, Hsueh T, et al. Primary Epstein-Barr virus infection associated with Kikuchi's disease and hemophagocytic lymphohistiocytosis: a case report and review of the literature. J Microbiol Immunol Infect. 2010; 43(3):253-7. Epub 2011/02/05. https://doi.org/10. 1016/S1684-1182(10)60040-0 PMID: 21291855.

14. Lim GY, Cho B, Chung NG. Hemophagocytic lymphohistiocytosis preceded by Kikuchi disease in children. Pediatr Radiol. 2008; 38(7):756-61. Epub 2008/05/23. https://doi.org/10.1007/s00247-008-0894x PMID: 18496683.

15. Nishiwaki M, Hagiya H, Kamiya T. Kikuchi-Fujimoto Disease Complicated with Reactive Hemophagocytic Lymphohistiocytosis. Acta Med Okayama. 2016; 70(5):383-8. Epub 2016/10/26. https://doi.org/10 18926/AMO/54597 PMID: 27777431.

16. Dumas G, Prendki V, Haroche J, Amoura Z, Cacoub P, Galicier L, et al. Kikuchi-Fujimoto disease: retrospective study of 91 cases and review of the literature. Medicine (Baltimore). 2014; 93(24):372-82. Epub 2014/12/17. https://doi.org/10.1097/md.0000000000000220 PMID: 25500707.

17. Kim YM, Lee YJ, Nam SO, Park SE, Kim JY, Lee EY. Hemophagocytic syndrome associated with Kikuchi's disease. J Korean Med Sci. 2003; 18(4):592-4. Epub 2003/08/19. https://doi.org/10.3346/jkms. 2003.18.4.592 PMID: 12923340.

18. Marsili M, Nozzi M, Onofrillo D, Sieni E, Chiarelli F, Breda L. Kikuchi disease, macrophage activation syndrome, and systemic juvenile arthritis: a new case associated with a mutation in the perforin gene. Scandinavian journal of rheumatology. 2015; 44(5):429-30. Epub 2015/05/15. https://doi.org/10.3109/ 03009742.2015.1033009 PMID: 25974073.

19. Hayden A, Park S, Giustini D, Lee AY, Chen LY. Hemophagocytic syndromes (HPSs) including hemophagocytic lymphohistiocytosis (HLH) in adults: A systematic scoping review. Blood reviews. 2016; 30 (6):411-20. Epub 2016/05/31. https://doi.org/10.1016/j.blre.2016.05.001 PMID: 27238576.

20. Grom AA, Mellins ED. Macrophage activation syndrome: advances towards understanding pathogenesis. Curr Opin Rheumatol. 2010; 22(5):561-6. Epub 2010/06/03. https://doi.org/10.1097/01.bor. 0000381996.69261.71 PMID: 20517154.

21. Grom AA, Horne A, De Benedetti F. Macrophage activation syndrome in the era of biologic therapy. Nat Rev Rheumatol. 2016; 12(5):259-68. Epub 2016/03/25. https://doi.org/10.1038/nrrheum.2015.179 PMID: 27009539.

22. Song $Y$, Wang $Y$, Wang Z. Requirement for etoposide in the initial treatment of Epstein-Barr virus-associated haemophagocytic lymphohistiocytosis. Br J Haematol. 2019. Epub 2019/05/23. https://doi.org/ 10.1111/bjh.15988 PMID: 31115044.

23. Ravelli A, Minoia F, Davi S, Horne A, Bovis F, Pistorio A, et al. 2016 Classification Criteria for Macrophage Activation Syndrome Complicating Systemic Juvenile Idiopathic Arthritis: A European League Against Rheumatism/American College of Rheumatology/Paediatric Rheumatology International Trials Organisation Collaborative Initiative. Ann Rheum Dis. 2016; 75(3):481-9. Epub 2016/02/13. https://doi. org/10.1136/annrheumdis-2015-208982 PMID: 26865703.

24. Ravelli A, Minoia F, Davi S, Horne A, Bovis F, Pistorio A, et al. 2016 Classification Criteria for Macrophage Activation Syndrome Complicating Systemic Juvenile Idiopathic Arthritis: A European League Against Rheumatism/American College of Rheumatology/Paediatric Rheumatology International Trials Organisation Collaborative Initiative. Arthritis Rheumatol. 2016; 68(3):566-76. Epub 2015/09/01. https://doi.org/10.1002/art.39332 PMID: 26314788.

25. Ahn SS, Yoo BW, Jung SM, Lee SW, Park YB, Song JJ. In-hospital mortality in febrile lupus patients based on 2016 EULAR/ACR/PRINTO classification criteria for macrophage activation syndrome. Semin Arthritis Rheum. 2017. Epub 2017/03/08. https://doi.org/10.1016/j.semarthrit.2017.02.002 PMID: 28268026.

26. Ahn SS, Yoo BW, Jung SM, Lee SW, Park YB, Song JJ. Application of the 2016 EULAR/ACR/PRINTO Classification Criteria for Macrophage Activation Syndrome in Patients with Adult-onset Still Disease. J Rheumatol. 2017. Epub 2017/04/17. https://doi.org/10.3899/jrheum.161286 PMID: 28412707.

27. Fardet L, Galicier L, Lambotte O, Marzac C, Aumont C, Chahwan D, et al. Development and validation of the HScore, a score for the diagnosis of reactive hemophagocytic syndrome. Arthritis Rheumatol. 2014; 66(9):2613-20. Epub 2014/05/02. https://doi.org/10.1002/art.38690 PMID: 24782338. 
28. Batu ED, Erden A, Seyhoglu E, Kilic L, Buyukasik Y, Karadag O, et al. Assessment of the HScore for reactive haemophagocytic syndrome in patients with rheumatic diseases. Scandinavian journal of rheumatology. 2017; 46(1):44-8. Epub 2016/07/01. https://doi.org/10.3109/03009742.2016.1167951 PMID: 27359073.

29. Jordan MB, Allen CE, Weitzman S, Filipovich AH, McClain KL. How I treat hemophagocytic lymphohistiocytosis. Blood. 2011; 118(15):4041-52. Epub 2011/08/11. https://doi.org/10.1182/blood-2011-03278127 PMID: 21828139.

30. Schulert GS, Grom AA. Macrophage activation syndrome and cytokine-directed therapies. Best practice \& research Clinical rheumatology. 2014; 28(2):277-92. Epub 2014/06/30. https://doi.org/10.1016/j. berh.2014.03.002 PMID: 24974063.

31. Barbat B, Jhaj R, Khurram D. Fatality in Kikuchi-Fujimoto disease: A rare phenomenon. World journal of clinical cases. 2017; 5(2):35-9. Epub 2017/03/04. https://doi.org/10.12998/wjcc.v5.i2.35 PMID: 28255545.

32. Behrens EM. Macrophage activation syndrome in rheumatic disease: what is the role of the antigen presenting cell? Autoimmunity reviews. 2008; 7(4):305-8. Epub 2008/02/26. https://doi.org/10.1016/j. autrev.2007.11.025 PMID: 18295734.

33. Agmon-Levin N, Rosario C, Katz BS, Zandman-Goddard G, Meroni P, Cervera R, et al. Ferritin in the antiphospholipid syndrome and its catastrophic variant (cAPS). Lupus. 2013; 22(13):1327-35. Epub 2013/09/17. https://doi.org/10.1177/0961203313504633 PMID: 24036580.

34. Shakoory B, Carcillo JA, Chatham WW, Amdur RL, Zhao H, Dinarello CA, et al. Interleukin-1 Receptor Blockade Is Associated With Reduced Mortality in Sepsis Patients With Features of Macrophage Activation Syndrome: Reanalysis of a Prior Phase III Trial. Critical care medicine. 2016; 44(2):275-81. Epub 2015/11/20. https://doi.org/10.1097/CCM.0000000000001402 PMID: 26584195.

35. Lerkvaleekul B, Vilaiyuk S. Macrophage activation syndrome: early diagnosis is key. Open access rheumatology: research and reviews. 2018; 10:117-28. Epub 2018/09/15. https://oi.org/10.2147/oarrr. S151013 PMID: 30214327.

36. Colafrancesco S, Priori R, Alessandri C, Astorri E, Perricone C, Blank M, et al. SCD163 in AOSD: a biomarker for macrophage activation related to hyperferritinemia. Immunologic research. 2014; 60(23):177-83. Epub 2014/11/13. https://doi.org/10.1007/s12026-014-8563-7 PMID: 25388964.

37. Crayne CB, Albeituni S, Nichols KE, Cron RQ. The Immunology of Macrophage Activation Syndrome. Frontiers in immunology. 2019; 10:119. Epub 2019/02/19. https://doi.org/10.3389/fimmu.2019.00119 PMID: 30774631. 